\title{
Considered Principally With Reference To The Measures Adapted For The Development Of Individual Excellence
}

\author{
Lieut.-Col. A. Cunningham Robertson
}

To cite this article: Lieut.-Col. A. Cunningham Robertson (1861) Considered Principally With Reference To The Measures Adapted For The Development Of Individual Excellence, Royal United Services Institution. Journal, 5:16, 87-107, DOI: 10.1080/03071846109416748

To link to this article: http://dx.doi.org/10.1080/03071846109416748

曲 Published online: 25 Sep 2009.

Submit your article to this journal $\pi$

山 Article views: 1

Q View related articles $\longleftarrow$ 
Friday, March 8th, 1861 .

The Right Hoxourable LORD LOVAINE, M.P. in the Chair,

\author{
MILITARY TRAINING \\ CONSIDERED PRINCIPALLY WITH REFERENCE TO THE MEASURES ADAPTED FOR \\ THE DEVELOPMENT OF INDIVIDUAL EXCELLENCE."
}

BY

Lieur.-Col. A. Cunninonam Rogertson, 8th (The King's) Regiment.

The subject of the address which I am about to read is of considerable practical importance, and I renture to hope that the discussion of it in this place may possibly lead to beneficial results.

If any of the suggestions which I shall have the honour of submitting to you be true in principle, and practically expedient, there are members belonging to this Royal Institution who have both the will and the porrer effectually to promote the adoption of any measure which may, in their judgment, be calculated to improve the efficiency of our military institutions.

But the utility of discussing such a subject as military training is, to a certain extent, independent of the correctness or incorrectuess of any particular conclusion.

Even although the considerations which $I$ am about to submit to you may not be sufficient to prove that any specific measure is expedient, yet these considerations will not be altogether destitute of value if they suffice to attract your attention to a particular aspect of the subject of military training, and if they tend to show that, in order to render the training process effective, we must endearour to render it interesting and attractive.

The efficiency of the training of an army depends-

Ist. Upon its comprehending provisions for the attamment of every species of knowledge and of every species of skill susceptible of a useful military application.

2nd. Upon the excellence of the methods of instruction made use of.

3rd. Upon the amount of time and energy which the officers and soldiers composing the army can be compelled or induced to devote to the work of instruction.

It is principally to the third of these three essential conditions of a complete system of military training that $I$ am at present anxious to direct your attention.

I shall endeavour to present to you, with as much fulness as the time at my disposal will permit, an exposition of those means which, it appears to

* Several extracts from an axticle contributed by the author to Colburn's United Service Magazine in November, 1856, are incorporated in this paper. 
me, are likely to operate most efficaciously in inducing the officers and soldiers of an army to devote to the work of training that amount of time and energy which it is indispensably necessary should be devoted to that work, in order to secure the development of individual excellence.

But before entering upon this exposition, it will be convenient to say a few words regarding the nature of the objects of military training, and the principles that must determine the selection of the means which are appropriate for the attainment of these objects.

The question-What is the object of military training? may perbaps be most perspicuously answered by changing its form, and asking what qualifications are desirable for the perfect performance of the duties of the different military grades?

Bravery, strength, agility, habits of obedience and temperance, skill in the use of arms, expertness in drill and in the various exercises, operations, and processes incident to service in the field,-these are the qualities, the possession of which constitute a thoroughly efficient prirate soldier; to which must be added, if he belongs to the cavalry branch of the service, a perfect knowledge of all that relates to the management of horses.

In addition to these, a non-commissioned officer should possess the rudiments of education. He should possess a sound knowledge of reading, writing, arithmetic, and book-keeping.

Ascending to the next grade: firmness, energy of character, equanimity of temper, skill in horsemanship, a thorough familiarity with the principles and special provisions of military law, and with the rules and regulations of military service, together with an elementary knowledge of the scierces of artillery, fortification, military history, military geography and tactics, are the additional qualifications necessary to constitute an accomplished regimental officer.

Attainments, the same in kind, but superior in degree, are those which it is desirable should be possessed by staff officers and officers of the corps of Engineers.

An officer selected for either of these special services should be thoroughly acquainted with the principles and familiar with the practical applications of the sciences of artillery, fortification, and military engineering.

He should have attentively studied the history of the principal modern campaigns, and should be well acquainted with the military geography of the countries which trere the theatres of those campaigns. He should be master of the special tactics of cavalry, infantry, and artillery, and of the theory of strategy and general tactics. He should be a clever draughts. man, an expert surveyor, and so good a linguist as to be able to speak and write fluently the principal modern languages, and to be able to acquire with facility a colloquial knowledge of any other dialect which may be spoken in the country in which he is serving.

Finally, let us suppose an officer who, possessing many of the attainments and all the qualities desirable for the performance of all the duties of the staff with perfect efficiency, shall also be pre-eminent for the firmness, the energy, the self-reliance, and the resolute boldness of his character; for a penetrating sagacity quick to detect the designs of an enemy, and for inventive faculties ever ready to devise skilful combinations, and to arrange 
well-digested plans. In a word, let us suppose military genius to be united to military science, and we have the perfect model, the beau idéal of an accomplished general.

All the particulars of this detailed enumeration of the qualifications desirable for the perfect performance of the duties of the different military grades are comprehended in the general statement, that the two great objects of military training, are-

First. To impart to the individual officer, and to the individual soldier, whatever qualities, whatever kinds of knowledge, and whatever species of skill, are necessary to enable him to fulfil every function of his grade in a perfect manner.

Second. To instruct soldiers and officers collectively in regular systematic modes of performing all exercises, operations, and processes which are necessary for the purposes of offensive or defensive warfare, or which are conducive to the comfort and efficiency of troops employed in field service.

The objects of the processes of individual and of collective training, though perfectly conpatible with one another, are essentially different in their nature.

Each object requires for its attainment the use of certain specific means, and, as will be afterwards shown, the means appropriate for the attainment of the object of individual training are radically different in principle and in their manner of operation for their attainment of the object of the processes of collective training.

In a perfect system of training, suitable provision will be made for the attainment of both objects; and if either be neglected, the troops will, in certain respects, be inefficient and imperfectly fitted for the purposes of war.

In the middle ages we have an example of a system in which individual training was carefully practised, and collectire training altogether neglected.

The many interesting and exciting circumstances attending the celebration of tournaments, the wide-spread renown, the high personal distinction, the favour of the fair, and the admiration of the brave, which were the rewards of the victors in those splendid trials of skill, were means admirably fitted to fill the ranks of the mediæval armies with soldiers thoroughly accomplished in the use of their arms, and skilful in every warlike exercise.

But these soldiers, individually terrible in battle, were destitute of that collective training necessary to render them proportionably formidable when acting in masses, necessary to render the results such soldiers were capable of achieving proportional to the numbers employed.

The modern method of training armies, introduced by the great Frederick, furnishes anexample of a system precisely opposite to that of the middle ages.

In this system, the sole object aimed at is to regulate the movements of masses of troops with mathematical precision.

Individual training, except in so far as it is subservient to collective training, is altogether neglected.

The recruit, after going through a process of setting-up drill, and being taught how to face in whaterer direction he may be ordered, is very carefully trained so to regulate the length and quickness of his pace as to be able to march steadily at a perfectly uniform rate of motion.

$\mathrm{He}$ is also taught to go through the manual and platoon exercises. 
This, previous to the Crimean war, was the whole amount of individual training bestowed on our infantry soldiers.

To devclope individual excellence, or in any way to turn to account the special endowments or acquirements of the infantry soldier, was not, either directly or indirectly, the object of this training.

Its sole object was to ensure precision and uniformity in the subsequent processes of collective training.

It may, perhaps, be said that the annual ball practice had a different object; but though ball practice was no doubt intended to train men to hit the mark, that is, to use their arms skilfully, it was so conducted as to be quite incapable of producing any effect as a means for obtaining this end.

In the year 1844, when quartered in Dublin, I have known a regiment march down to the sands at the Pigeon House, and expend, in a single day, the whole of the season's allowance of practice ammunition, which was got rid of principally by firing volleys into the sea.

Previously to the adoption of the Hythe system of musketry instruction, ball firing was practically nothing more than the last lesson in the platoon exercise. It taught the recruit to load, and accustomed him to the recoil of a ball cartridge. This was all it actually did. This was all that, in the nature of things, it was capable of doing.

To find an example of a system in which due provision was made both for individual and collective training, we must go back to the military institutions of the Romans.

In the time of Julius Casar the admirable legions of that great military power were perhaps the most perfectly trained and the most formidable troops ever employed in warfare.

Not only were these legions collectively instructed in all the processes necessary for the accurate formation of the line of battle, and for enabling its position or direction to be changed with the utmost possible rapidity, but the personal qualities of each individual legionary soldier, his bodily vigour, and his expertness in the use of his arms, were carefully cultivated by the assiduous practice of appropriate methods of training.

The Romans did not consider it sufficient that their soldiers should excel in that training which enables the united efforts of the feeble to overcome the separate efforts of the strong, which makes a disciplined band of pigmies more than a match for an undisciplined mob of giants; they were also solicitous so to train their soldiers that each individual soldier, when acting by himself, should feel himself superior to his adversary.*

Since the time of Frederick, to render the soldier individually superior to his adversaries has not been an object of military training in European armies.

Regularly trained European soldiers when acting together in masses are formidable, but those regular troops who defeated the Highland clans at Culloden, or the Mamelukes at the Pyramids, would, generally speaking, have felt themselves no match for their adversaries in individual combats.

There can be no stronger proof of the excellence and of the great

- In No. 12, rol. iv. of the Journal of the Institution will bo found an intereating sketch of the military institutions of the Romans. 
aportance of collective training, than the well-ascertained fact that regular woops are able to contend successfully against adversaries superior to them woth in numbers and in personal qualities.

But although the conditions of modern warfare are such, the completeBo of the collective training of troops is a more important element of * than the perfection of their individual training, yet it would be a very great mistake to suppose that personal qualities have little or no influence in modern warfare, and that the development of individual excellence by appropriate training processes will have little or no influence in increasing the efficiency of an army.

In studying the circumstances of such combats as Culloden or the Pyramids, the point on which it is profitable to fix our attention is not on the results which follow when tro bodies of troops contend, one of which is deficient in collective and the other in individual training, but on the results which might be expected to be obtained by troops equally perfect in both kinds of training if matched against adversaries inferior to them in either the one or the other of those kinds.

The individual training of the private infantry soldier should embrace instruction in-

1st. Marching and setting-up drill.

2nd. In gymnastic exercises, including swimming.

3rd. In the use of his arms and of entrenching tools.

4 th. In field cookery.

His collective training should embrace instruction-

1st. In field exercises and evolutions.

2nd. In heavy gun drill and in the management of artillery.

3rd. In the method of constructing trenches and batteries in presence of an enemy.

4th. In escalading.

5th. In the method of pitching tents and constructing huts.

6th. In the method of using tackles, and in the modes of applying some of the simpler mechanical contrivances for moving heary bodies.

In addition to all that is taught the private soldier, the training of officers ought to include regular and systematic instruction-

1st. In the regulations of military service.

2nd. In military law.

3rd. In the method of tracing field works, and of distributing working parties.

4th. In the method of attacking and defending posts, and of conducting the various minor operations of warfare.

I imagine there would be no difficulty whatever in devising inexpensive arrangements for habitually exercising infantry soldiers in erery process and operation which forms part of the regular training of a gunner belonging to a reserve company of artillery.

I do not, however, forget that the special training of the sapper is a costly process, and one which cannot be carried on excepting under conditions which it would be impossible to fulfil, and with appliances which it would be impossible to procure, at many stations where infantry are quartered.

But although some of the processes in which the sapper is instructed 
could not be taught at all to the infantry soldier, and although others could not be taught. hy the same methods and in the same complete manner in which they are taught to the sapper; yet I feel sure there are many engineer officers (say, Col. Harness or Lieut.-Col. Bainbrigge) who could organise a system of instruction in the method of using tools, tackles, and simple machines, and in the most effective means of applying combined labour to produce specific results, suitable to the opportunities for instruction afforded by the ordinary conditions of the service of an infantry soldier.

In order to provide men qualifed to act as instructors to train the soldiers to labour, and as overseers to direct and superintend their work when actually emploged in any manual operation, a regularly trained sapper might be attached to each company in the capacity of pioneer.

Officers who had passed through the Staff College, when not holding Staff appointments, might also be advantageously emplojed as agents for carrying out any system that might be devised for exercising infantry soldiers in some of those processes which at present form part of the specialitics of the training of the sappers.

The state, which maintains during peace, at a vast expense, a great body of men whose sole occupation is to render themselves fit for the purposes of wiurfare, has a right to expect that the training of these costly servants shall be not only more perfect in degree, but also more comprehensive in its scope, than the instruction hurriedly given to militiamen, raised for temporary service.

It has a right to expect that the term "regular soldier" shall denote not merely an unskilled labourer wearing a particular uniform, but a man who, having undergone a long apprenticeship, is accomplished in every species of knowledge and every species of skill which has any special practical relation to the varied exigencies of military service, who has been sedulously trained in all arts which render a man formidable in battle, who has been carefully instructed in all expedients which enable him to overcome the difficulties and efficiently to assist in the labours of a campaign.

I have now stated what I conceive ought to be the objects of military training. The means arailable for the attainment of these objects are,-

1st. Systematic collective instruction.

2nd. The independent prosecution of military studies, and practice of military exercises by individuals.

Whatever kinds of knowledge and whatever kinds of skill it is essential that every officer or every soldier should possess for the efficient performance of the ordinary functions of his grade, ought to be communicated by regular systematic instruction.

The acquisition of those kinds of knowledge and skill which are only applicable in special circumstances, and which it is only necessary that a certain proportion of the officers or soldiers of an army should possess, need.not be made imperative on any one.

It is not necessary to make the acquisition of reading and writing imperative on every soldier, or the acquisition of mathematics and of the military sciences imperative on every officer of an army.

Provided some special emolument or distinction be conferred on all who possess special attainments, it may be left to the discretion of each indivi- 
do determine both the number and degtee of the acquirements of this ind which he shall possess, and also to determine what particular means, -d what amount of exertion, are necessary for the attainment of his object. Having thus indicated a general principle, which will serve to determine nature of the means which are suitable for the attainment of the ieferent objects of military training, I shall not attempt to enter into any -tails respecting the specialities of different processes of instruction, but I to refer to the paper which was read in this place in. June last, by Captain Jerrois.* It contains very interesting statements regarding the results of gymnastic training in continental armies, and points out rery simple arrangements by which gymnastic training might be carried out, not only in barracks and permanent camps, but even in the field.

In confirmation of Captain. Jervois' opinion, that it is practicable to carry on gymnastic training, even during the operations of a campaign, I may mention that during the recent Indian campaign the engineer officers attached to Sir Thomas Seton's column carried about with them posts and bars. At almost every halt these were set up, as soon after the morning's march as the tents were pitched; and in the evening these officers used to amuse themselves by practising gymnastic exercises.

The next point to be considered is the means by which the officers and privates of an army may be induced to devote their time and energies to the work of instruction.

These means are, -

1st. The infliction of penalties.

2nd. The distribution of rewards.

Either of these means may be employed by itself, or the two may be combined.

In the category of penalties must be included, not only the ordinary punishments inflicted on soldiers for the careless performance of prescribed exercises, but also all regulations making the promotion of officers and non-commissioned officers contingent on their possessing certain prescribed qualifications.

In order to form a correct opinion as to whether it is sufficient to enforce the use of any particular training process by compulsory means, or whether, either instead of or in addition to such means, those inducements should be also employed which are adapted to stimulate voluntary exertion, regard must be had to the nature of the result which that particular process is intended to produce.

In some training processes the result sought is, that all who are instructed should attain precisely the same uniform degree of average proficiency. In others, that each separate individual should attain the highest degree of excellence of which he is capable.

If only ten men of a company one hundred strong can be trained to become first-rate marksmen, it is very desirable that these ten men should be made as perfect as possible, without any reference whatever to the degree of skill which it may be practicable to impart to the remaining ninety: But if one hundred men of a regiment one thousand strong could be taught to execute six mancuvres, while the remaining nine hundred could only be made to comprehend the method of executing four, the superior knowledge

" See Vol. IV. page 370. 
of the first hundred would be of no use until the same amount of instruction could be conveyed to all the other soldiers. Nor, in performing field exercises, would any advantage whatever be gained by training a certain percentage of the men of a regiment to march at a rate considerably quicker than that of the regulation pace, unless it were found practicable to train every other soldier of the battalion to march steadily at the same accelerated rate.

These illustrations will suffice to show what I mean, when I say that the objects of individual and of collective training are different; that in the one, excellence-in the other, uniformity-is the result sought.

In those processez in which uniformity is the essential object to be attained, it is obvious that all differences of individual power are injurious, and that the use of those means which are calculated to stimulate voluntary exertion and to develope individual excellence can have no place.

In those processes, on the other hand, in which the utmost possible degree of individual excellence is the result which we desire to obtain, it is esscntial that the methods of instruction should be rendered as attractive as possible, and that, by the use of appropriate means; the desire to excel should be generally diffused amoni those who are to be instructed.

$\Lambda$ s a necessary condition for the general diffusion of a desire to excel, provision must be made for discriminating different degrees of acquirement, and for making special advantages contingent on the attainment of the higher degrees.

The efficiency and fitness of any system of training for the development of individual excellence, will, therefore, mainly depend on the efficacy of the means employed to excite and diffuse the desire to excel.

If those parts of military training, which admit of the discrimination of degrees of acquirement, are ever generally regarded by soldiers with disgust, as an irksome drudgers, this state of feeling may be accepted as a conclusive proof that the system of training is defective, and that proper provision has not been made for giving soldiers a beneficial interest in successful exertion.

Until very recently, when on the substitution of rifles for muskets in the armament of infantry, the classification of soldiers, according to their skill as marksmen, was adopted as part of the admirable method of musketry instruction organised by General Hay, our system of military training was entirely compulsory in principle.

It contained no provision for discriminating degrees of any one of the various acquirements which it is desirable that soldiers should possess, nor did it contain the restige of any other provision calculated to favour the development of any kind of individual excellence.

In each of the grades of the military organisation, from the grade of the drummer to that of the general, the sole object aimed at was to communicate a certain minimum of such kinds of instruction as were absolutely indispensable to all who performed the functions of that grade.

The system took no account whatever of those inherent differences of capacity and energy, or of those various degrees of acquirement, which distinguish man from man.

Talent was not rewarded; zeal was not encouraged; precise systematic uniformity was reckoned the one essential object; implicit obedience the one essential condition of successful training. 
In order to estimate what amount of efficiency is likely to be the result of a system of training which contains no provision for creating a desire to excel, which offer to individuals no inducement to strive after excellence, let any one consider what would be the effect on the learned professions if the infuence of individual exertion in procuring the honours and emoluments of these professions ceased when the young barrister obtained his gown, or the young physician his diploma: if the bench ceased to be the prize of superior legal ability, if riches and social eminence were no longer the reward of superior medical skill: or, since the ability of the soldier cannot in time of peace be manifested by successfully contending with the practical difficulties of military service, but, like the aptitude of a young man to succeed in life, can only be imperfectly measured by the completeness of his preparntory training, let us choose an illustration more strictly analogous, and consider how learning would thrive in our schools and universities, if the distinction of academical honours and advantages of academical endowments ceased to stimulate students to use their utmost exertions for the acquisition of learning.

If, then, experience prores that to make honours and emoluments the reward of excellence is a means which it is necessary to employ in order to produce able lawyers, skilful physicians, and accomplished scholars, surely it is reasonable to infer that we must employ means of the same kind if we wish to produce well-trained soldiers.

I think no one would deny that this inference is reasonable, were it not that the highest kinds of military merit are of such a nature that in time of peace it is not only impossible to measure their degree, but it is not even possible to ascertain their existence with certainty.

Courage is the highest merit of a soldier. Courage, firmness of purpose, energy of character, natural sagacity, and inventive genius are the highest merits of an officer. But these qualities can only be made manifest in time of war, when occasions arise for their exercise. How, then, some may argue, is it possible to discriminate the degrees of merit existing among the individuals of an army? How is it possible to apply the principle of developing individual excellence to a system of military training?

It would indeed be impossible to do so, if no qualities possessed military value excepting those which must necessarily remain latent during peace, or if, in order to reward an individual for well-ascertained excellence of a particular kind, it were indispensably necessary to ascertain that he was endowed in an eminent degree with some other quality, the existence or non-existence of which we did not possess the means of discovering.

But besides courage, are not strength, agility, skill in the use of arms, qualities which are necessary to constitute a good soldier?

Besides military genius, is not knowledge of the military sciences, and skill in the practice of military arts and exercises, necessary to constitute an accomplished officer? Are not these qualities of a nature to be at all times, in peace as well as in wrar, patent to obserration?

As exhibited in different individuals do they not all admit of differences of degree, and may not these differences be measured with tolerable accuracy?

It is, indecd, very probable that the best shot in a company might not be the bravest soldier-that the most scientific officer in a regiment might 
not be endowed in the same degree with energy, prudence, and the inventive faculties.

But though it may be exceedingly difficult, or, let us rather say, absolutely impossible, before troops have gone through the ordeal of warfare, to determine absolutely who is the best soldier in a company, who is the best officer of a regiment, or who the best general of an army, surely this is no reason why we should not reward superiority in any particular quality which it is advantageous that every soldier, every regimental officer, or every general should possess-wherein it is desirable that every individual of every one of these ranks should use his utmost efforts to excel.

These considerations seem to me sufficient to show that the old system of training by methods exclusively compulsory was defective, and to render it extremcly probable that the efficiency of the training of the army might be greatly increased by the adoption of measures based on this fundamental principle, that it is expedient to confer some special adcantage, either peciniary or" honorary, on erovy individual, whether officer or soldier, utho attains a certain degree of proficiency in any art, exercise, or science susceptible of a useful military application, and in which it is desirable that each individual should endeavour to excel.

In considering what particular measures are best fitted to give practical effect to this principle, regard must of course be had to the different degrees of importance which attach to the various qualities, arts, exercises, and sciences which it is the end of military training to develope or to teach.

A careful estimate must also be made of the manner in which the working of any proposed measure is likely to be affected by the other provisions of our existing military institutions. We must consider whether the interests which are the result of those provisions are likely to favour or likely to oppose the smooth working of the measure.

Since the invention of gunpowder was effectirely applied in warfare, great battles have generally been decided without actual collision between any considerable masses of the infantry of the hostile armies; and the recent improvements in the construction of fre-arms have greatly increased the distance at which infantry can fire with precision, and consequently act with effect.

To render the infantry soldier a good marksman, ought therefore undoubtedly to be considered the primary object of his individual training.

The classification of soldiers according to their skill as marksmen, which forms so prominent a feature in the new system of musketry instruction, appears to me the most efficacious means which it is possible to devise for promoting this object.

It is a measure which has completely altered the character of military training.

Formerly, the process of training a soldier merely consisted in compelling him to practise daily for a certain number of hours a regulated mechanical routine; now, this process has become the acquisition of an art requiring the exercise of the soldier's intelligence and the co-operation of the soldier's will. Formerly it was an irksome drudgery, now it has become an interesting and profitable occupation.

This change in the nature of the soldier's training necessarily elevates his position as regards other classes of the community. 
Formerly he belonged to the class of unskilled labourers, whose scrvices reeive only a uniform rate of remuneration; now he belongs to the class which practises those arts in which differences of skill command different rates of wages. As compared with the sister service of the Royal Navy, the elassification of soldiers, according to their skill as marksmen, may be regarded as according to the army that recognition of individual merit which has always been enjoyed in the navy, by the method of rating which divides the crew of a ship into the two classes of able and ordinary seamen.

The improvement in the conditions of military service effected by raising the soldier from the class of unskilled labourers to the class of craftsmen skilled in an art, is to be estimated not merely with reference to the pecuniary interests of the soldier, but chiefly with reference to the influence which this change is calculated to exert on his moral state. In order justly to appreciate the nature of the improvement, we must endeavour to estimate the moral effect of a change which opens to every soldier a career offering inducements to continual exertion, and admitting of a progress towards perfection, which, though constant, can, practically speaking, never reach a limit-a career which operates on every soldier who enters upon it by giving a salutary impulse to his apathetic feelings, a useful direction to his listless thoughts, and a profitable occupation for his idle hours.

If the administration of the Duke of York was memorable for improvements effected in the discipline and organization of the army, the administration of the present Commander-in-Chief is likely to be no less memorable for the new principle which, under the auspices of His Royal Highness, is now being introduced in our system of military training.

In the course of a few years, when experience has made us familiar with the manner in which this new principle operates, we shall gradually become thoroughly sensible of the potent influence which, when judiciously applied, it is calculated to exert on the training of troops. Improtements will, no doubt, be made in the details of existing regulations, and I think it may be expected that new measures will be devised affording additional inducements to the acquisition of military skill, and tending to increase the interest felt by officers and soldiers in the success of the training process.

$I$ trust $I$ shall not be reckoned presumptuous if I venture to submit to you some suggestions and conjectures respecting the additional means which, sooner or later, it may possibly be found expedient to adopt for promoting these useful objects.

An examination of the figures given in General Hay's last Report (1859-60), seems to show that the regulation restricting the number of marksmen who may be recommended for increased pay to 10 per cent. of the number instructed, is unnecessary; and that, without exceeding the prescribed limits of expense, every soldier might be recommended for increased pay who scores the number of points and fulfils the other conditions which entitle him to be classed as a marksman.

From the data given at page 41 of the Report, it appears that-

The number of men exercised was

Ten per cent. of this number would be

But the number of qualified marksmen only amounted to about three and a half per cent. of the number instructed. Out of the number qualified there were recommended for increased rates of pay

vol. $\mathrm{V}$. 
The remainder were ineligible because, in a few particular corps, the number of marksmen exceeded ten per cent. of the number instructed; the number of men thus rendered ineligible was about $3 \cdot 6$ per cent. of the number qualified. The amount of extra pay recommended in the Heport is . $\$ 6,348 \quad 190$ Which is equivalent to an allowance for each man instructed of about

Had ten per cent. of the number instructed been recommended for increased rates of pay, the sum required rould have been equivalent to an allowance for each man instructed of .

This, then, is the anomalous result presented by the report of the year's practice; the number of men qualified to be recommended for an increased rate of pay is much less than ten per cent. of the number exercised, and yet the number actually recommended is considerably less than the number qualified.

In the present state of the instruction of the army, it is therefore evident that the regulation restricting the grant of increased pay to a certain percentage of the number instructed, if it be merely intended to act as a limit to expenditure, is unnecessary.

This end is practically secured by the high standard of qualification which must be attained to entitle a soldier to be classed as a marksman.

The manner in which the restriction really acts is most injurious and unfortunate. Its direct effect is to interfere in an arbitrary manner with individual interests by depriving a certain proportion of the soldiers in a few of the most highly trained corps of those advantages to which, as far as personal merit is concerned, they have probably, in many cases, a better right than some of the men of other corps to whom these advantages are accorded.

The indirect effect of the restriction is to lessen the motives to exertion, by making those advantages, which should in every case be the certain reward of skill, in some cases to depend on arbitrary couditions altogether beyond individual control.

A restriction which is unjust to individuals, and which is an obstacle to the attainment of efficiency, without being necessary to secure economy, may be confidently pronounced to be unadvisable.

Indeed, I should esteem the restriction inexpedient, even if it were shown in a satisfactory way that the number of marksmen was likely to exced ten per cent. of the number exercised, and that the difference between the value of the services of a good and a bad marksman was so small, that $3 s$. $6 l$. for every man instructed was the limit of the sum which could bo profitably expended for the purpose of increasing the percentage of marksmen.

In distributing a fund appropriated to furnish premiums for successful exertion, whether that fund be large or small, the one principle of distribution which it is essential should be adhered to, disregarding all other considerations, is this,--That all the conditions necessary to be fulfilled in order to establish a claim to the premium should have reference to personal qualifications; that none of them should be arbitrary and depending on circumstances over which individual exertion has no control.

Whatever sum be therefore assigned as the amount not to be exceeded in 
granting premiums to marksmen, I should consider it a better provision for limiting the expenditure, to raise the qualification, than to restrict the number eligible for premiums to a certain percentage of the number inutructed, thereby rendering liable to exclusion some of those who had fulfilled all the conditions which had reference to their personal qualifications.

At Hythe, where most of those instructed are picked men, and where the training process is carried on under the most favourable conditions, the proportion of marksmen to the number instructed among the non-commissioned officers and privates is only 101 per cent.* It is not, I imagine, likely that the average results of the regimental practice of the army will erer be so good as those obtained at the school of instruction.

Supposing, however, the general training of the army was so much improved, that more than ten per cent, of the number trained scored 7 points in the first class, I think it would be better to raise the qualifications of a marksman to 8 or 9 points, than to exclude a certain number of those who were able to score seven points from the advantages given to others who possessed no higher qualification.

The liability of the annual course of instruction to be interrupted before all the practices are completed, or to be rendered imperfect by being conducted at places where the full extent of range is not to be obtained, are other circumstances over which the soldier has no control, which affect his chance of obtaining a musketry premium.

However skilful he may be, one or other of these contingencies may prevent the possibility of his obtaining the increased rate of pay, or, if he has already obtained it, may prevent his keeping it for more than a single season.

In the regiment to which I belong, in two successive seasons, both times after the men had worked hard, and gone through a great part of the practices, it unfortunately happened that the course of instruction was unavoidably interrupted, and the men were twice disappointed of those rewards, the hope of obtaining which had been a source of much interest and excitement.

The disappointment occasioned congiderable irritation and dissatisfaction. One man, in particular, who volunteered to remain in India when the regiment was ordered home, came to the orderly room and urged that his right to a premium should be registered as an unsettled claim.

I cannot help fearing that the remembrance of these two seasons of disappointed exertion will have a tendency to render the men careless and apathetic, and that for some years to come the results of the practice of the regiment will not be so good as if the new system had been introduced under more favourable circumstances.

One mode in which the distribution of premiums might be rendered independent of the condition of a corps being able to complete the whole course of instruction, would be to substitute, instead of the present uniform test of qualification, a variable test, depending on the ratio of points made to shots fired, the ratio diminishing as the length of range increased.

A percentage of 100 points in the third class, of 75 points in that

* Vide Report, p. 5.

II 2 
second class, and of 35 points in the first class, might, for instance, be established as the standard of performance which entitled a soldier to be classed as a marksman.

Or, if it be considered essential, as it is no doubt desirable, that the original test of qualification should in every case be the same, a variable test might certainly be admitted as a sufficient proof that a soldier who had once undergone the standard uniform test, and who had been classed as a marksman, was qualified to retain his rating.

It seems perfectly just and proper that all soldiers drawing extra pay on account of superior skill should be liable to the periodical repetition of the original test of qualification; but when circumstances prevent the test being repeated, it is certainly neither just nor expedient to inflict the penalty of failure; and to deprive a soldier of extra pay, whose skill, instead of having diminished, may very possibly have increased, and of which increased skill it is even possible he may be exhibiting proofs more real and conclusive than that proof of skill which is afforded by a soldier scoring 7 points in the first class at target practice.

To illustrate this, let us suppose a case which must frequently occur:-

Would it be expedient in time of war to grant a higher rate of pay to those marksmen of a regiment who remain with the depôt, and whose skill is merely exhibited at target practice, than to those with the service companies, who are displaying equal, or, very possibly, higher, degrees of skill in actual contests with the enemy?

In addition to the increased rate of pay granted at the end of the annual practice to those soldiers classed as marksmen, another measure might be adopted which would render skill at target practice, in exact proportion to its degree, in every case, a certain source of advantage to the soldier.

Small premiums for every point made might be distributed to the soldiers on parade at the conclusion of each day's practice, say, for instance, one halfpenny for ranges up to 300 yards, onc penny for ranges between 300 and 600 yards, and twopence for ranges between 600 and 900 yards.

The superior influence of that which is present and sure, to that which is doubtful and remote, is more or less felt by all men; but it is felt in a very strong degree by men who, like the generality of soldiers, are deficient in moral and intellectual culture.

Most soldiers would prefer four or five shillings paid on the spot in ready money, to the promise of an allowance of a penny a-day, to commence after an interval of several months.

A given sum of money distributed day by day on parade in small payments, and in which distribution almost every one shared, would, I think, be found to have a greater effect in rendering target practice interesting, and in stimulating soldiers to use their best efforts to fire well, than a much larger sum allotted at the end of the season to increase the pay of a percentage of picked marksmen.

The worst marksman would have the same interest as the best to shoot carefully. since, when the unskilful soldier was lucky enough to make a point, it would be estimated to be of the same value, and would be recompensed by the same premium, as if fired by a soldier who never made a miss. 
Taking for data the figures recording the practice of the lst Battalion, 22nd Regiment, the best shooting battalion of the year, I calculate that the sum requisite for the payment of premiums according to the scale I have suggested, that is, one halfpenny, one penny, and twopence per point for the third, second, and first class ranges, would be about $2 s$. $31 d$. for ench man exercised in the complete annual course of instruction. This may be regarded as a maximum.

Taking for data the figures recording the practice of the 85th Regiment, which stands seventy-first in the list, showing the comparative merit of different corps, and which is therefore selected as a suitable corps for obtaining average results, I find that in the present state of the instruction of the army, the cost of distributing premiums for every hit on the scale proposed would not exceed $1 s .7 \frac{1}{2} d$. for every man who completes the course.

Between four and fire shillings is the sum which a good marksman would receive in premiums during the season's practice.

If it be admitted to be beneficial to give soldiers a direct interest in the success of their exertions to become skilful marksmen, I think it may be presumed that a similar effect might be expected to be produced by employing similar means to influence the exertions made by commanding officers and musketry instructors to render the training of their corps as perfect as possible.

One means of giving those who have the superintendence of musketry instruction a beneficial interest in its success, would be to make a certain proportion of their pay consist of an allowance varying in amount in the same ratio as the proficiency of the corps, as shown in the practice returns.

Five pounds for every unit in the figure of merit of the corps might be allotted for distribution in certain fixed proportions between the com. manding officer, the musketry instructor, and his assistants.*

In the case of the commanding officer, this variable allowance might be substituted for the three shillings per diem command money, which he at present receives.

When the practice was not carried far enough to admit of a figure of merit being established, the amount of the allowance might be regulated either by the percentage of points made to shots fired, or by reference to the practice of former seasons.

It is no doubt'true, that the success of the training of a corps depends in a greater or less degree on various circumstances, over which those who have the direction of the process of instruction have little or no control.

Nevertheless, I think there can be little doubt but that one of the chief causes which produces the very great differences between the performances of different corps, which must strike every one who examines General Hay's report, is, differences in the capacity and energy which exist among officers commanding battalions and their musketry instructors.

If this be the case, to make part of the emoluments of these officers

- At this rate, when the figure of merit was $40,40 \times 5=£ 200$; and when the figure of merit was 30,30 $35=f 150$-would be the amount of the sum to be distributed. This might be allotted in the proportion of three-fifths to the commanding officer, in lieu of his command money, and two-fifths to the muaketry instructor and his assistants. 
consist of a variable allowance, regulated in the manner $I$ have suggested, would be a measure not merely expedient, but also perfectly equitable in principle. The possibility in any exceptional case of inflicting individual hardship, might be obviated by so adjusting the scale of the variable allowance to existing rates of pay, that, while those who received the higher rates should obtain a premium, those who received the lower should not suffer a fine.

Another measure of a wider scope, not restricted in its object to the improvement of rifle practice, but calculated to promote the efficiency of every part of the physical training of soldiers, would be the institution of periodical trials of skill, and the distribution of prizes to those among the competitors who were the most skilful in the use of their arms, or who. excelled in any of those athletic exercises which are calculated to develope the qualities of agility and strength.

These periodical trials might be so organized, as to act as a most powerful stimulus both to officers and soldiers. They should be of three classes-regimental, district, and national. The regimental trials should be held annually at the head-quarters of each corps, the prizes being open to the competition of every member of the corps-of the officers as well as of the privates.

The district trials should be held annually in the principal gazrisons and head-quarters of military districts both at home and abroad.

No officer or soldier of the regular forces should be permitted to contend for a prize at these district competitions, unless he had previously gained a prize at the regimental trial of a corps quartered in the garrison or district; but soldiers of the militia, and members of volunteer and local and irregular corps should also be admitted as competitors.

The national competitions should be held biennially or triennially at Windsor.

Any individual who, in the interval between two successive celebrations, had been a rictor in a district competition, should have a right of competing for the national prizes; and, if a soldier of the regular army, in whatever part of the empire he might be serving, he should have the privilege of being conveyed to Windsor at the public expense.

The degree of interest which would attach to the reginental and district trials, and consequently the influence of the proposed measure as a means of increasing the efficiency of military training, would principally depend on the greater or less degree of social distinction which public opinion might confer on the winner of a prize at the national competition.

In proportion to the amount of social distinction awarded to the winner of a prize, and not in proportion to the pecuniary value of the prize itself, would be the eagerness with which prizes would be desired, and the strenuousness of the efforts made to obtain them.

Every means should therefore be used calculated to increase the eclat of victory, and to render the celebration of these national trials of military skill a splendid and imposing spectacle.

The prizes should-be distributed by the hand of the Sovereign. The pomp of ancient heraldic observances should give dignity to the ceremonial of the distribution.

Considering the amount of local excitement caused by the exhibition of 
athletic exercises at Highland or Border gatherings, and the. still more bively interest felt by large classes of the community in the result of ericket matches, boat races, and volunteer rifle matches; considering also how widely the minutest details of every event are diffused by the press, and how vividly they are pourtrayed by photographic and pictorial illustrations, I think it cannot be doubted that the celebration at Windsor of national trials of military skill would attract vast assemblages of deeply interested spectators, and that, throughout the length and breadth of the land, multitudes of all classes of the community would be prepared to sympathise with the objects of their institution-multitudes who would listen with eager interest to the accounts of the contests for the various prizes, and in whose mouths the names of the victors would become familiar household words.

To be recognised as the best shot, the swiftest runner, the most expert swordsman, or the most accomplished horseman in the army, is a distinction that would be contended for not more eagerly by the private soldier than by the commissioned officer.

It is a distinction that would be appreciated not less highly in the aristocratic mansions of the metropolis, than in the humble cottages of the remote provincial hamlet.

I do not think it possible to form an exaggerated estimate of the effect which the hope of obtaining such a distinction would have on the physical training of the army.

The influence exercised by this motive would be same in kind, and perhaps not much inferior in degree, to that which operated on those heroic warriors who in ancient times contended for prizes at the Olympic games, or on the noble chivalry who, in the middle ages, eagerly pressed into the lists at tournaments to win, by the display of strength of limb and skill in arms, the love of women and the praise of men.

If almost ercry privato who entered the ranks, if alnost every officer who obtained a commission, could be induced to devote himself with ardour and perseverance to the voluntary practice of those exercises which develope the bodily powers and make men dexterous in the use of arms, can it be doubted that the result of those voluntary exertions would be the attainment of higher degrees of individual excellence, and also of a higher general average of strength, agility, and skill, than it would be possible to attain by the most rigorous system of compulsory training ?

The institution of national military competitions, in addition to the beneficial effect which it might be expected to have in improving the training of the troops of the line, scems to be a measure peculiarly fitted to exercise an influence favourable to the permanence of the volunteer organisation.

The interest and excitement of trials of skill in which personal distinction is the reward of success, would be regarded by multitudes of young men as a fair equivalent for the sacrifices of time and money which are exacted from members of volunteer corps.

In time of actual war, or when the risk of war appears imminent, to secure the country from invasion is felt to be the most urgent of necessities, the most sacred of duties. In such circumstances, feelings of patriotism and a sense of personal danger are sufficient motives to induce men freely 
to make whatever sacrifices of time and money may be required from them, and zealously to derote themselves to military training, hokerer irksome or laborious the process of instruction may be.

l3ut in times of profound peace, when no danger threatens, it appears to me a delusion to expect that rolunteer corps can be kept together, and their members induced to persevere in the practice of military exercises, unless means can be devised to render these exercises attractive, and to render the fulfilment of the duties of a voluntcer the means of obtaining some privilege, some advantage, or some distinction which is an object of general desire.

The sum necessary to provide an adequate prize fund for periodical competitions, arranged according to such a scheme as I have detailed, might be estimated at an allowance of

El per company, or about $21 d$. per man, for the regimental competitions ;

$£ 5$ per battalion, or about $1 \frac{1}{2} d$. per man, for the district; and

$£ 10$ per battalion, or about $3 d$. per man, for the national competitions: making for the prize fund of the three classes a total of about $7 d$. per man.

If all the measures which have been discussed were adopted; if, in addition"to the extra pay granted to marksmen, premiums were distributed for every point made at target practice; if successful musketry instructors received increased allowances; and if prizes were awarded at periodical competitions to all who excelled in any military or athletic exercise; if, moreover, it be assumed that the effect of these measures was to make every corps in the army shoot as well as that corps shot this year which stands first in General Hay's report, the whole cost of these measures, including both the increase caused by the use of additional means, and that caused by increased efficiency, would not exceed $5 \mathrm{~s}$. $9 \frac{1}{2} \mathrm{~d}$. per man.

That is to say, the additional cost of training 62 soldiers, caused by employing such means as I have suggested, would be equal to the pay of a single soldier.

A reduction of about one and a half per cent. in the establishment would therefore provide sufficient funds for earrying out these measures without any increase of the army estimates, and I think it might be fairly expected that this small reduction in the numerical strength of our military forces would be much more than compensated by the increased efficiency which would probably result from rendering the training process as attractive as possible, and from making each individual soldier feel that he had a strong personal interest in becoming as perfect as possible in every military exercise.

I now pass on to the consideration of the measures suitable for promoting among officers the acquisition of those special attainments which require a certain degree of intellectual exertion, and which must be acquired by study in the closet.

The general principle to be observed in framing measures intended to promote voluntary study, is to leave as much latitude as possible to the exercise of individual inclination in the selection of the particular subjects to be studied-not to estimate merit solely by reference to one exclusive standard, requiring the combination of a certain number of particular 
dkainments, but to admit of as many different standards of merit as there we different kinds of attainments.

The value of that superior merit which consists in the union of many different attainments, is exaggerated when the circumstance of union is eonstituted the essential condition on which the entire value of each partieular attainment exclusively depends, without the existence of which condition, any particular attainment, however perfect in degree, is to be reckoned altogether valueless. The true principle is to assign to each particular attainment a certain specific value, and, where tro or more are combined, to assign to their union a cumulative value proportioned to their number.

Let the first place be assigned to him who is ignorant of nothing which an officer ought to know; but do not overlook the merit of any one who excels in a single useful speciality. Do not insist upon a good linguist being also a good mathematician. Do not refuse to reward a skilful draughtsman because he is a bad artillerist, or because he is ignorant of military history.

In addition to the provisions which at present exist for the admission of officers to the Staff College, and for the selection of officers for Staff appointments from among those who have passed salisfactory examinations in the prescribed course of college studies, it therefore seems to me that it would be highly desirable to provide: That any regimental officer, under the rank of a field officer, adjudged by a central board of examiners to be proficient in any extensively spoken living language, whether Oriental or European, or to possess in an eminent degree any other species of knowledge or skill susceptible of a useful military application; should receire increments to his daily pay, and have distinguishing letters attached to his name in the Army List, corresponding to the number and degree of his attainments.

These increments might vary from sixpence to one shilling per diem, according to the relative difficulty and importance of the attainments to be rewarded. Four or five shillings per diem might be fixed as the maximum of the aggregate increments to be awarded to any one individual.

The maximum rate should be added to the pay of all officers under the rank of field officer, and not actually holding a Staff appointment, who obtain a Staff College certificate.

All such officers should also be registered in the Army List as Staff supernumeraries, and, when not on parade, they might be permitted to wear the uniform of the Staff.

I think it quite certain that measures such as these, putting it in the power of every individual officer to earn a large addition to his pay, and also to secure for himself the distinction of being affiliated with the Staff of the army, and the contingent advantage of being nominated to honorable and lucrative appointments, would have the effect of inducing a large number of young officers to devote their leisure time to the assiduous study of some one or more of those branches of knowledge the possession of which would increase their efficiency as officers. In the course of a few years the average standard of attainment would be considerably raised; and the number of thoroughly accomplished officers qualified to perform in the most 
efficient manner the varied duties which devolve on the Staff would be greatly increased.

In order to obtain these results, it would of course be necessary so to regulate the standard of attainment as to place the rewards of proficiency within the reach of a considerable proportion of the regimental officers of the army.

This condition I think would be completely fulfilled, were the standard of attainment so regulated as to render it probable that on an average six officers per regiment would be able to earn an addition of one shilling per day to the pay of their rank; three officers an addition of two shillings, and one officer of three shillings. Extra rates of pay granted on this scale would cause an expenditure of fifteen shillings a day per battalion, which is a little less than the pay of three ensigns, and a little more than the pay of fourteen privates.

In endeavouring to estimate the effect of introducing a new measure into an established system, the probability of its combining harmoniously with the other parts of the system is a consideration to which it is most important that due attention should be given.

In the British army, as in all other armies, conspicuous bravery and conspicuous military talent, when service in the field affords opportunities for their display, always secure distinction and reward. But in time of peace, money is the only qualification recognised as giving a prior claim to promotion. Distinguished abilities or superior attainments in no way contribute to professional advaricement.

Amoug those who hold commissions in the army are many who, beyond that amount of knowledge necessary to carry on the routine duties of the arm to which they belong, know little and care less about military matters; many who, finding ignorance and want of zeal no impediment to their rising to the highest rank in the army, are utterly averse to sacrifice their ease, or to interrupt their favourite pursuits, in order to devote their timo and their energies to the acquisition of knowledge which they consider as not likely to be productive of any practical benefit. Not a few of these officers, by long habits of idleness and self-indulgence, have rendered themselves unfit for any intellectual exertion. They have become quite incapable of making that effort of will necessary to keep the attention steadily fixed on any object for a considerable length of time. Officers of this character form a very numerous class in the senior as well as in the junior ranks of the army; and such being the case, it is obvious that uny attempt to raise the standard of attainment by means of a compulsory character would have to contend with many obstacles. Not only would such an attempt be very unpopular, it would meet with much practical opposition of a very effective kind.

In many corps, the feeling of the commanding officers would be hostile to compulsory measures; and if the officers commanding those corps did not dare actually to oppose such measures, they would use no exertions to carry them out.

In other corps, where the commanding officers might be well disposed to carry them out, it might sometimes happen that they were not qualified to do so. Not being themselves sufficiently instructed, they would fail in their 
forts to instruct others. In other cases, it might happen that a zealous and thoroughly instructed commanding officer, by carrying out his measures with too great stringency, would create so much disgust as to defeat his awn object.

These are some of the considerations which seem to render it inexpedient, if not altogether impracticable, to enforce the possession of any high degree of educational attainment, as an indispensable qualification for promotion. Measures based on the principle of offering inducements to voluntary exertion would have no difficulties of this kind to contend with; no extra duties, no compulsory labours, would be imposed upon any one; there would therefore be no motive for opposition. On the contrary, every individual in every rank of the army would be interested in the success of messures which, without coercing idleness or imposing penalties on incapacity, recognised the claims of zeal, of industry, and of talent, and which offered a sure reward to every species of military acquirement.

Any measures framed in accordance with this principle would not only disarm opposition, they could not fail of conciliating a large amount of active support; nor would such measures be liable to the risk of failure from the negligence, the incapacity, or hostility of the agents employed to carry them out.

The most perfect system of compulsory training, unless administered with energy, intelligence, and zeal, will soon degenerate into a formal routine; but there is no danger that the voluntary exertions of those who strive for a promised reward will relax, however incompetent or indifferent the persons may be who are appointell to decide who is to receive that reward.

Almost every one of the observations which I have had the honour of submitting to you, have been suggested to my mind by looking at the conditions of . military service in time of peace from that particular point of view which takes cognizance of the relations subsisting between these conditions and the feelings aud interests of individuals.

The result of a survey from this point of view is to disclose a defect and to suggest a remedy. The want of any motive to stimulate individual exertion, is in time of peace the great disadvantage of a military carcer. This is the defect. The obvious remedy is to devise expedients for making each individual officer and each individual soldier feel that some special distinction or advantage may be procured by his own exertions.

Those particular measures which I have discussed in detail, and which I have endeavoured to show are fitted to accomplish this purpose, are seven in number, viz.:

1st. The classification of soldiers according to their skill as marksmen, and the grant of extra pay to all in the first class.

2nd. The distribution of premiums for every point made at target practice.

3rd. The payment to the officers and non-commissioned officers entrusted with the direction of musketry instruction of an allowance varying according to the figure of merit of their corps.

4th. The institution of periodical trials of skill, and the distribution of prizes for excellence in rifle-shooting, swordsmanship, horsemanship, and athletic exercises. 
5th. The grant to officers of extra rates of pay for special attainments.

6 th. The affliation with the Staff of the army of all officers who reach a certain standard of attainment.

7th. The selection for appointment- on the Staff of those officers who are the most distinguished for their abilities, for their attainments, and for their services.

It will be perceived that in the fourth and seventh of these proposed measures-namely, those which relate to the institution of periodical trials of skill and to the selection of officers for Staff appointments-the principle by which merit is estimated and rewards distributed is competitive, and has reference to a variable standard. The nature of this principle is to restrict, within fixed limits, the number of individuals who can derire direct benefit from these two measures.

In all the other measures the principle of estimate and distribution is absolute-it has reference to a fixed standard, and admits of an unlimited number of individuals participating in the benefits of each of the different measures.

The practical effect of these measures would therefore be to render a certain addition to the allowances of officers and to the daily pay of privates contingent on successful exertion-to make each individual feel that, whaterer may be his rank, and whatever the nature of his duties, if zealous and efficient he will receive more, if careless and inefficient he will receive less.

The importance of measures such as these, and the effect they are likely to have in increasing the efficiency of the training of the army, is to be estimated by considering the nature and amount of the influence they are calculated to exert on the disposition with which soldiers regard the work of instruction, by considering what influence they are likely to exert in counteracting feelings of apathy and dislike, what influence in promoting energy and inspiring zeal.

It is manifestly of the greatest importance to render not only as efficient as possible, but also as attractive as possible, the training of an army which is numerically weak, and of which the limited establishment is wilh difficulty maintained effective, because the name of no soldier is inscribed in its muster rolls without his own consent. 